\section{Health Data in the Information Age: Use, Disclosure and Privacy}

\author{
Edited by Molla $S$ Donaldson and \\ Kathleen N Lohr, Washington DC, \\ National Academy Press, 1994, \\ 257 pages, $\$ 32.95$.
}

Health Data in the Information Age is the report of a multidisciplinary committee of the US Institute of Medicine, composed largely of clinical directors and information technology experts. It examines the development of technology which has allowed data to be aggregated into vast sets, and considers both the potential for good and harm arising from such informatic power.

The report should be read with two provisos in mind. First, the Health Database Organisations (HDOs) which it considers, are thought of as secondary records, distinct from an individual patient's medical record. This distinction allows the editors more easily to dismiss concerns over the unauthorised viewing of confidential health information, on the grounds that the databases will largely contain information that cannot be identified with any one patient. Concerns relating to prurient hackers, journalists and other undesirables breaking into the system(s) are thus alleviated. This distinction also means that the law relating to primary medical records (for instance, with regard to compulsory disclosure of notifiable diseases or gunshot wounds) would not apply to the HDOs, prompting the committee to recommend specific federal legislation.

The second limitation on the report is one that it itself acknowledges, although it sees it as a strength: it is that databases of the sort envisaged and discussed remain, as yet, on the informational drawing board. This gap between the status quo and the brave new world of the database means that the report is forced to project somewhat into the future - "eventually", "perhaps", and "one day" occur repeatedly. The enthusiast would argue that this represents a commendable attempt to shape technology before we are shaped by it, and would not be unduly concerned at the gap between vision and practice in health informatics. The more reserved sceptic might be inclined to wait to see what in fact was on the technological menu before he or she placed an order.

Perhaps it is this concern that the report should be as much a vision of the future as a consideration of the present that forces the editors to adopt a relentlessly technical style. The tone of the report is no clearer than might be expected from a sixteen-strong committee, even one composed of computer experts: its thirty pages of definitions and eighty-odd acronyms scarcely persuade the ordinary intelligent reader to linger, although it has a more useful twenty-five page summary.

It is to the report's credit that it recognises that the problems associated with health data collection and release go beyond standard issues of confidentiality and the privacy of celebrities. The editors, for instance, canvas concerns surrounding the amassing of performance data from individual units and extrapolation from such data, warning that simple aggregation of figures will not necessarily produce a useful ordinal ranking.

The report's conclusions are perhaps not entirely surprising, ranging from the frankly banal (that database managers ensure that their data are reasonably accurate) to recommendations derived from existing law and views on the confidentiality of medical records. This linkage between current practice relating to paper records and future electronic data lends support to the editors' views that the ethical and legal concerns surrounding data collection are the same whether these data are stored in a filing cabinet or on a networked computer. If this is so, then the report's desire for new federal legislation to regulate collection and dissemination of health data in electronic format calls into question the present law's adequacy to protect even paper records.

The report is interesting as an example of how the possibilities and challenges of the much-vaunted information age are being addressed in a medical setting. Although its treatment of its concerns is hardly new, its account of the developing landscape of health informatics is of some valuese There is an extensive bibliography.

RUPERT JARVIS

Centre for Philosophy and Health Care, University of Wales, Swansea, Singleton Park, Swansea SA2 8PP

\section{Ethics for Everyone - a Practical Guide to Interdisciplinary Biomedical Ethics Education}

\section{C Grafius, Chicago, American Hospital Publishing Inc, 1995, 223 pages, US \$49.pb.}

The author of this book has set out to write an introduction to education in biomedical ethics (for which, depending on your location and preferred jargon, read health care ethics, bioethics or medical ethics); and not only to education but to interdisciplinary education in these areas. For this reason we might have expected a book aimed amongst other things, at convincing teachers of health care ethics that they should teach ethics in an interdisciplinary context. As an intro- 
ductory text relating to education in bioethics, we might have expected a broad introduction to the kinds of issues with which teachers of ethics in medicine should be concerned and to some ways in which they might build ethics into the education of doctors, nurses and other health care workers.

Grafius does give an introduction of a kind to education in biomedical ethics. For example, she gives an overview of some of the topics that might feature in a biomedical ethics education programme, though it is worth noting that most of these, other than issues of consent, hover around questions relating to death and terminal illness. She offers some guidance about the construction of such a programme and gives a step by step guide to a "process for ethical thinking and reflection" - a kind of "beginner's guide to ethical decision-making". This detailed procedural guide to ethical thinking might be particularly useful for those whose experience of wrestling with the dilemmas thrown up by practice is limited, and for practitioners who feel paralysed by their inability to make ethical choices. They should, of course, beware of the possibility of falling into the trap of believing that having followed the procedure laid down, the decisions they make will necessarily be the right ones; in any event such an approach, though useful in the initial stages of developing one's ability in ethical thinking, must in my view, eventually be laid aside.

Grafius has written Ethics for Everyone from a particular professional and cultural context and much of what she has to say about bioethics education - for example, about its scope, when it should take place, and for whom it should be provided, is perhaps of limited interest to those who do not work in similar contexts. The book contains no index, which is always a source of some annoyance. It does, however, contain a substantial bibliographical section containing references to texts (both general and topic-specific), videos and journals dealing with medical ethics; interestingly, though some non-North American books appear, the fournal of Medical Ethics is omitted from the list of relevant periodicals as is the journal Bioethics, which I would consider an important international contribution to any library serving health care ethics education. Lists are also given of centres dealing in issues in bioethics; again the focus is on North American centres.
This book is best regarded as a source for those who are already involved in teaching ethics to health care professionals. For example, it is a source of ideas for those who are unable to develop pedagogical tools of their own, or who want to learn some new tricks. One such idea is that of the "biomedical ethics grand round" - a formal affair where topics or particular cases are presented and discussed in an organised and formal interdisciplinary setting. One possible advantage of such an approach to working on ethical problems, is that the formality of the setting might make it easier for colleagues of different disciplines and different status to negotiate solutions, if solutions there are, to particular problems. On the other hand a formal setting might help to perpetuate certain myths, including the idea that seniority and status necessarily convey moral rightness.

Further to her discussion of biomedical ethics "grand rounds" Grafius offers a number of other "educational tools" designed to help participants in classes to become aware of various things - mostly, but not exclusively about themselves about their attitudes to death and mortality, about the source and nature of their moral beliefs, and about their relationship to significant others. Many of the tools offered focus on aspects of death and dying and this brings me to a weakness in the book as an introduction to biomedical ethics education in general - the limited range of issues that are addressed.

Following on from the discussion of these exercises is a chapter about the use of role play, which includes many vignettes which are suggested as the basis for role plays of various kinds. Role play is a valuable tool which can have great power to move but, perhaps as a consequence of this, must be handled carefully. As was the case with the educational tools I have already discussed, I am not convinced that Grafius gives sufficient guidance about its use. She offers both an overview of role play and its uses and some instructions about how to go about setting role-playing situations. However, I do not think this is sufficient to allow those who might use this book as an introduction to biomedical ethics education to use the interesting scenarios she offers to good effect, and more importantly, safely. My view is that role play is used too lightly by too many people who would do well to sensitise themselves to its power. Grafius makes clear that she does not think that role play should be used in isolation, but rather as part of a broader educational experience. In my view it should only be used by those who have given considerable time to learning how it might be used, perhaps as part of a course of study in dramatherapy or psychodrama.

Perhaps the most useful feature of this book is the fact that it contains some ready-made topics for discussion or, in the right hands, for exploration through action - whether in a mock "grand round", through role play, or through other narrative forms. All of this material would have been much more useful if it had been accompanied by discussion of the ethical issues raised, and by more substantial discussions of the ways in which the material - in particular the pot pourri of case studies and vignettes offered for role play - might be used. DR GAVIN J FAIRBAIRN
North East Wales Institute of Higher
Education

\section{Long-term Care Decisions: Ethical and Conceptual Dimensions}

Edited by Laurence B McCullough and Nancy L Wilson, Baltimore, Maryland, Johns Hopkins University Press, 1995, 246 pages, $£ 33$ hc.

This book is valuable reading for anyone working in the field of long-term care, and indeed for anyone working in the field of bioethics. The book provides a thorough and systematic analysis of the complex issues and influences involved with long-term care decision-making, and offers recommendations for adequately accounting for the importance of these. The value of the book can be measured by the fact that one can find oneself disagreeing with a particular substantive position which is proposed, while simultaneously realising the important contribution made in identifying the issue to be addressed.

The book is divided into five sections, each containing two to three chapters. The first section of the book examines historical and social forces which have influenced long-term care. 